\title{
40. Electron Microscope Observation of the Motor Cell of Mimosa pudica L. III
}

The Fine Structure of the Central Vacuole in the Motor Cell*)

\author{
By Hideo ToriYama,**) and Syôiti SATô***) \\ (Comm. by Tetsu Sakamura, M. J. A., March 12, 1969)
}

It is becoming increasingly apparent that the central vacuole of the motor cell of Mimosa pulvinus contains diffused fibrils which have been precipitated after stimulation (Toriyama and Satô 1968a, $1968 \mathrm{~b})$. In the present work the results of an investigation of the fine structure of these fibrous contents in the central vacuole of the motor cell will be reported in detail.

Generally, fixatives have a tendency to make the figure of the fine structure in the protoplasm easily noticeable in electron microscopy. In our previous papers the fine structure in the Mimosa motor cell, which had been fixed with osmium tetraoxide, was investigated. Now, we have attempted to compare these results with the effects of the fixation with potassium permanganate. An electron microscopical examination of the motor cell has been made.

Materials and methods. The main pulvini of Mimosa pudica L. were fixed for 2 hours with a $2 \%$ potassium permanganate solution and then embedded in methacryl resin according to the standard procedure. Observations were made by the use of an HS-type electron microscope made by Hitachi Company. In order to examine the motor cell before stimulation, the plants were exposed to ether vapour for 25 to 30 minutes as usual.

Experimental results. Electron micrographs of the motor cell of the main pulvinus before stimulation are shown in Figs. 1 to 4 . In the motor cell the cytoplasmic layer (cy) exists at the periphery of the cell, but the tonoplast is not in any clear-cut, observable condition (Figs. 1, 3 and 4). This finding is different from that in the case of the material fixed with osmium tetraoxide, where the tonoplast was clearly observed (Toriyama and Satô 1968a, 1968b).

It must be noted, however, that the fine structure of the contents in the central vacuole is very clearly visible in the potassium per-

*) This research has been supported in part by a Grant-in-Aid for Scientific Research from the Ministry of Education.

*:*) Biological Section, Tokyo Woman's Christian College, Tokyo.

***) Department of Biology, Japan Women's University, Tokyo. 


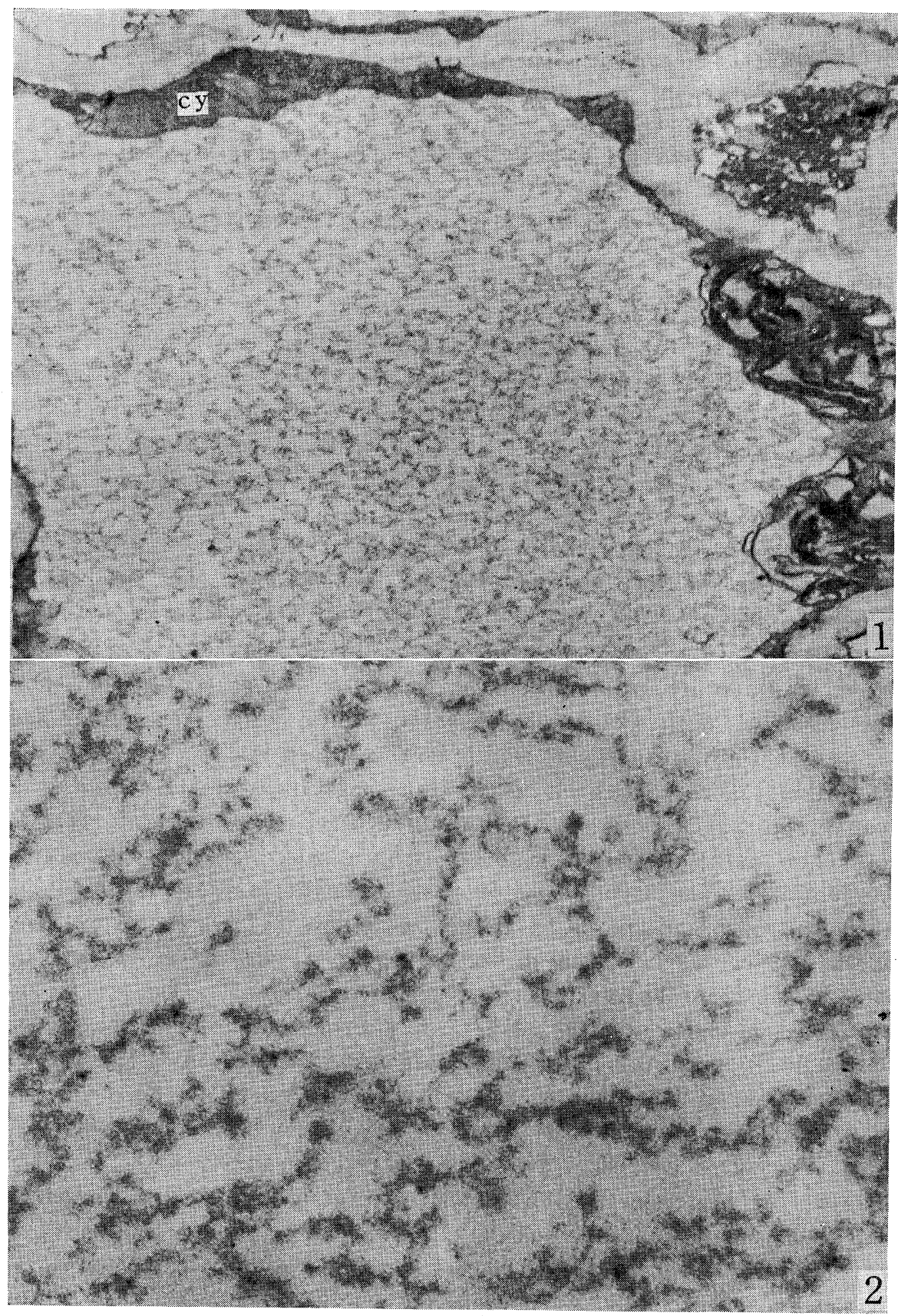

Fig. 1. Motor cell of main pulvinus of Mimosa pudica L. before stimulation. cy; cytoplasm. $\times 10000$.

Fig. 2. A part of the central vacuole of the motor cell of Fig. $1 . \times 30000$. Both microphotographs were produced from cell materials fixed with $\mathrm{KMnO}_{4}$. 


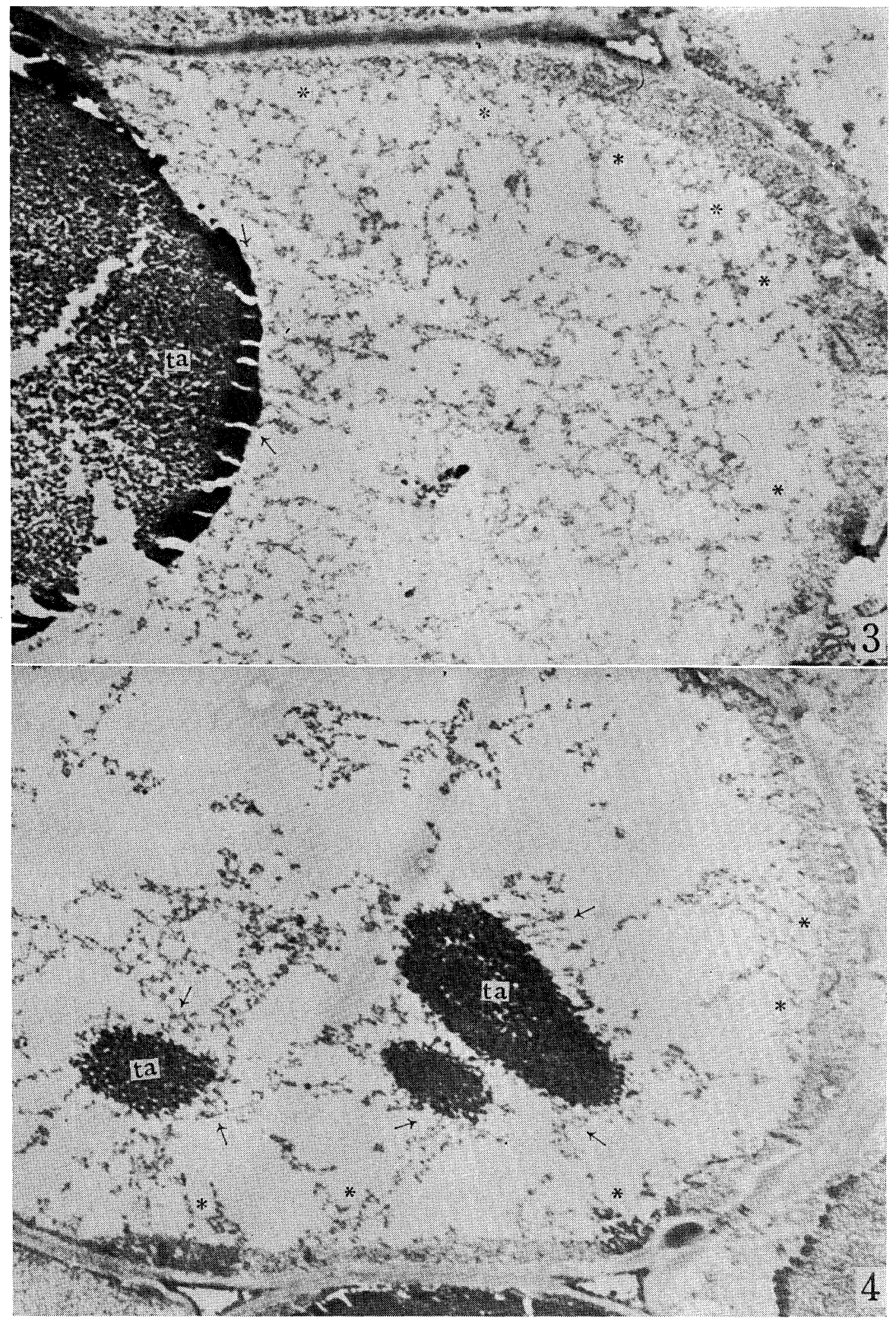

Figs. 3, 4. Motor cell of main pulvinus of Mimosa pudica L. before stimulation. Arrows indicate the connection between the surface of tannin vacuole and fibrils in the central vacuole; asterisks indicate the connection between the cytoplasmic layer and fibrils in the central vacuole. ta: tannin vacuole. $\times 9000$. Both microphotographs were produced from cell materials fixed with $\mathrm{KMnO}_{4}$. 


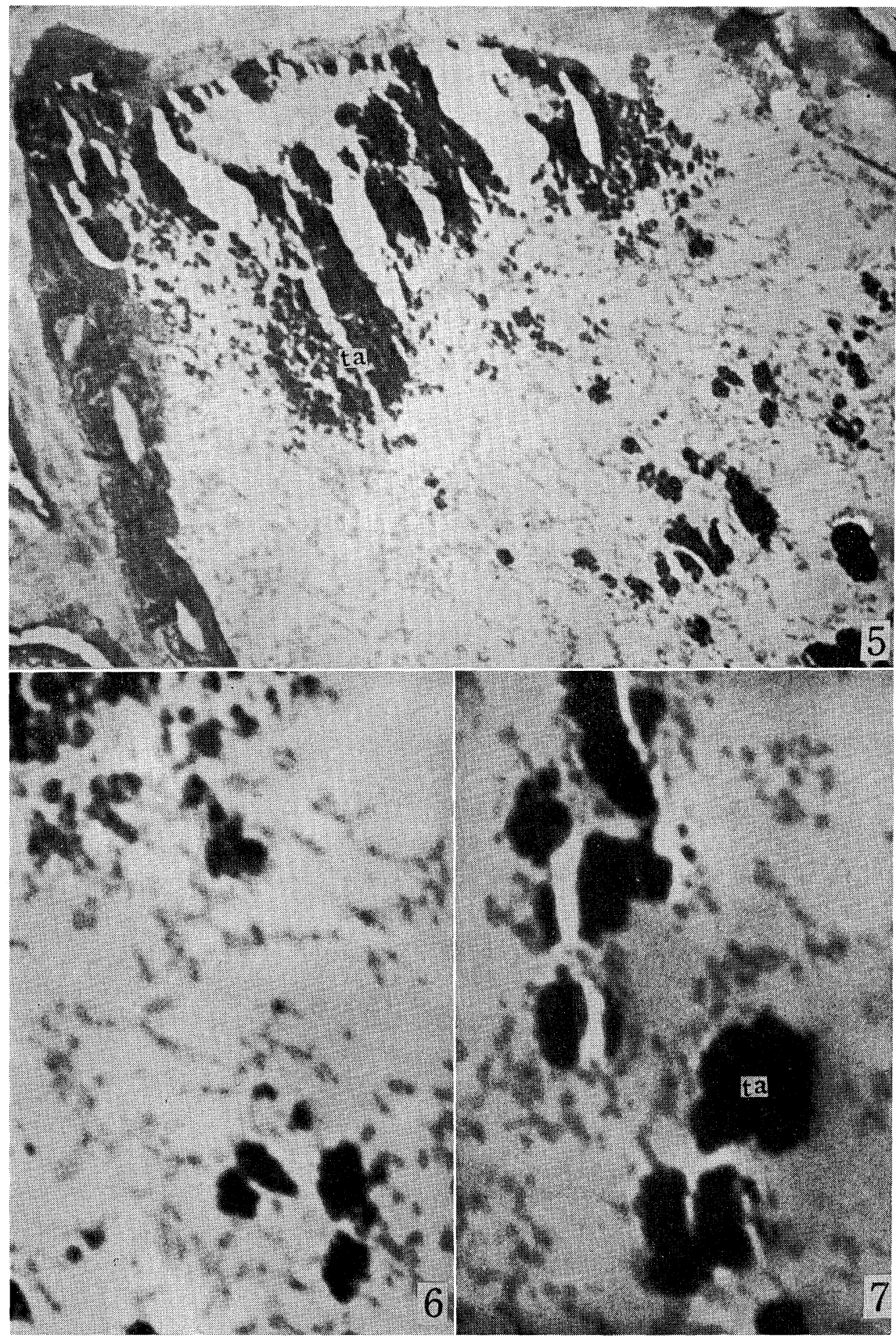

Fig. 5. Motor cell of main pulvinus of Mimosa pudica L. after stimulation. ta: tannin vacuole. $\times 9000$.

Figs. 6, 7. A part of the central vacuole of the motor cell of Fig. 5. ta: tannin vacuole. $\times 22500$. Above three microphotographs were taken from cell materials fixed with $\mathrm{KMnO}_{4}$. 
manganate material (Figs. 1, 2, 3 and 4). Before stimulation, diffused fine fibrils appeared; they were $30-60 \mathrm{~m} \mu$ thick and 400 $600 \mathrm{~m} \mu$ long. In general, the fibrils which are found in the material fixed with the potassium permanganate assume a swollen, thread-like structure, as is shown in Fig. 2. Sometimes some were present in the central vacuole of the cell (Fig. 1), but the contents were less clearly visible in other cells (Figs. 3 and 4 ).

It is noticeable that the fibrils are connected with the surface of the tannin vacuole (indicated by arrows) and also with the cytoplasmic layer (indicated by asterisks), as Figs. 3 and 4 show. Furthermore, the surface of the tannin vacuole (ta) appears to be electron-dense (Fig. 4). Thus, the cytoplasmic layer and the fibrous contents of the central vacuole and the tannin vacuole seem to have some connection with each other before stimulation.

The electron micrographs of the motor cell after the stimulation are shown in Figs. 5 to 7 . Under the stimulated conditions the tannin vacuoles were crushed and became electron-dense bodies (Figs. 5, 6 and 7). The fragments of the fibrous contents of the central vacuole were gathered near the crushed tannin vacuole (Figs. 6 and 7). When Figs. 2, 3, 4, 5, 6 and 7 are compared, it becomes evident that morphological changes in the fibrous contents occur in the central vacuole after the stimulation.

From the results presented above it may be concluded that the fibrous contents in the central vacuole and the tannin vacuole exist in relative positions making it possible for them to react with each other. The bio-physico-chemical reaction of the fibrous contents and of the tannin vacuole will undoubledly be elucidated in more detail in future research.

Acknowledgement. The writers wish to express their gratitude to Dr. Masako Osumi of Japan Women's University for her generous assistance in carrying out the electron microscopy.

\section{References}

Toriyama, H., and Satô, S. (1968a): Electron microscope observation of the motor cell of Mimosa pudica L. I. A comparison of the motor cell before and after stimulation. Proc. Japan Acad., 44, 702-706.

(1968b): Do. II. On the contents of the central vacuole of the motor cell. Proc. Japan Acad., 44, 949-953. 